\title{
O campo organizacional e a adoção de práticas estratégicas: revisitando o modelo de Whittington
}

\author{
The organizational field and adoption of strategic practices: revisiting Whittington's model
}

\author{
Silvana Anita Walter ${ }^{1}$ \\ Paulo Otávio Mussi Augusto ${ }^{2}$ \\ Valéria Silva da Fonseca ${ }^{3}$
}

\begin{abstract}
Resumo
Neste ensaio teórico, tem-se como objetivo desenvolver um modelo conceitual que possibilite relacionar os diferentes níveis de estratégia de forma a promover a integração entre as perspectivas institucional e de estratégia como prática, com mediação da teoria da estruturação. Para tal, adapta-se o modelo de Whittington (2006) por meio dos conceitos de isomorfismo; recursividade entre agência e estrutura; e propriedades estruturais. Assim, discute-se a relação existente entre mecanismos isomórficos institucionais e as práticas estratégicas adotadas pelos estrategistas de uma organização. Também se utiliza a concepção de que a ação dos estrategistas de uma organização é influenciada e influencia o campo organizacional, bem como é orientada pelas regras e recursos existentes no campo organizacional. Com base no modelo proposto, apresentam-se diferentes possibilidades de pesquisa que podem ser exploradas em estudos futuros. Conclui-se que as abordagens institucional e da estratégia como prática podem ser integradas como forma de ampliar seu enfoque. Isso poderá contribuir para que os estudos realizados sob essas perspectivas não se limitem a um nível de análise, mas busquem relacionar os fenômenos analisados em seus diferentes âmbitos e influências. Assim, tais abordagens poderão alcançar maior grau de conhecimento acumulado e de amadurecimento. Com o modelo proposto é possível contribuir igualmente para uma visão mais abrangente da estratégia, uma vez que abarca diferentes níveis que a integram.
\end{abstract}

Palavras-chave: teoria institucional; estratégia como prática; isomorfismo institucional; práticas estratégicas; propriedades estruturais; recursividade entre agência e estrutura.

Artigo submetido em junho de 2010 e aceito para publicação em novembro de 2010.

1 Doutora em Administração pela Pontifícia Universidade Católica do Paraná; Professora do Programa de Pós-Graduação em Administração da Universidade Regional de Blumenau. Endereço: FURB/PPGAD - Programa de Pós-Graduação em Administração, Rua Antônio da Veiga, 140, Sala D-102, Victor Konder, CEP 89012-900, Blumenau, SC, Brasil. E-mail: silvanaanita.walter@gmail.com

2 Doutor em Administração pela Escola de Administração de Empresa da Fundação Getúlio Vargas (EASP-FGV); Professor Adjunto da Pontifícia Universidade Católica do Paraná. Endereço: PUCPR/PPAD - Programa de Pós-Graduação em Administração, Escola de Negócios, Rua Imaculada Conceição, 1155, Bloco Acadêmico, 1ํAㄱㅁ, Sala 103B, Prado Velho, CEP 80215-901, Curitiba, PR, Brasil. E-mail: paulo.augusto@pucpr.br

3 Doutora em Engenharia de Produção pela Universidade Federal de Santa Catarina; Professora Titular da Pontifícia Universidade Católica do Paraná; Endereço: PUCPR/PPAD - Programa de Pós-Graduação em Administração, Escola de Negócios, Rua Imaculada Conceição, 1155, Bloco Acadêmico, 1ํㅡㄹ, Andar, Sala 103B, Prado Velho, CEP 80215-901, Curitiba, PR, Brasil. E-mail: valeria.fonseca@pucpr.br 


\begin{abstract}
The aim of this theoretical essay is to develop a conceptual model that relates the different levels of the strategy concept by integrating institutionalism and strategy as practice perspectives with the structuration theory. To accomplish this task, we adapt the model proposed by Whittington (2006), including in the model the concepts of isomorphism; recursivity between agency and structure; and structural properties. Thus, the existing relationship between isomorphic institutional mechanisms (institutional approach) and adoption of strategic practices by the strategists of an organization (strategy as practice) is discussed. The concept that the strategists' action in an organization is influenced and influences the organizational field is also discussed, in addition to the adoption of strategic practices by the strategists being oriented by existing rules and resources in the organizational field. From the proposed model, different possibilities of research are presented that can be explored in future studies. A conclusion is reached that the institutional approaches and strategy as practice can be integrated as a way of broadening their approach. This may contribute so that the studies conducted under these perspectives are not limited to one level of analysis, but rather seek to relate the analyzed phenomena in their different spheres and influences. Thus, such approaches may achieve a greater degree of accumulated knowledge and maturity. The proposed model may also contribute to a more comprehensive strategy view, since it encompasses different levels that integrate it.
\end{abstract}

Keywords: institutional theory; strategy as practice; institutional isomorphism; strategic practices; structural properties; recursivity between agency and structure.

\title{
Introdução
}

A abordagem da estratégia como prática consiste em um movimento derivado dos estudos da prática na teoria social dos anos de 1980 (SCHATZKI; CETINA; SAVIGNY, 2001; RECKWITZ, 2002) e teve, na área de estratégia, sua primeira nota de pesquisa em 1996. De acordo com Jarzabkowski e Spee (2009), a estratégia como prática surge em virtude de um descontentamento de pesquisadores com a pesquisa convencional sobre estratégia diante da baixa relevância atribuída ao fazer estratégia e ao papel dos estrategistas. Assim, à luz dessa perspectiva, a estratégia é uma prática social na qual os estrategistas atuam e com a qual interagem (WHITTINGTON, 1996). Essa abordagem - embora busque relacionar os níveis da estratégia -, ao focar a atuação dos estrategistas em âmbito micro das organizações, arrisca-se a se limitar muito a esse aspecto (WHITTINGTON, 2006), o que torna importante relacioná-la com uma visão mais ampla.

A teoria institucional, em contraposição, concentra-se em níveis de análise que podem revelar a dimensão intersubjetiva de significados compartilhados - e que dotam a vida social de sentido -, ou seja, tende a focar o nível mais macro. No entanto, atualmente, emerge um debate na pesquisa institucional sobre a dimensão micro de análise organizacional, o que, para Palmer, Biggart, Dick (2008), é importante no sentido de integrar essa abordagem a outras que concebem a influência de fenômenos institucionais nas interações sociais.

Dessa forma, assume-se que as perspectivas institucional e da estratégia como prática podem se complementar de forma que a conversação entre elas possibilite que se relacionem os âmbitos micro e macro de análise da estratégia. Nesse sentido, o objetivo neste ensaio é desenvolver um modelo conceitual que relacione os diferentes níveis da estratégia de forma a promover a integração das abordagens teóricas referidas.

Para atingir esse objetivo, discute-se a relação existente entre isomorfismo - conceito oriundo da abordagem institucional - e adoção de práticas pelos estrategistas de uma organização - advinda da abordagem da estratégia como prática. Em pesquisa bibliográfica sobre estudos nacionais e internacionais baseados na abordagem da estratégia como prática, verificou-se que essa perspectiva foi aliada à institucional. Todavia, nessa conexão, efetuou-se uma relação com conceitos como legitimidade, institucionalização, contexto 
ambiental de referência e discurso institucional. Não foi encontrado estudo que a relacionasse ao isomorfismo institucional.

Além de considerar a influência exercida pelo ambiente institucional por meio dos mecanismos isomórficos institucionais, no estudo ora apresentado se supõe que existe uma influência mútua entre ambiente institucional e ação organizacional. Dessa forma, faz-se uso dos conceitos de recursividade entre agência e estrutura, e de propriedades estruturais, oriundos da teoria da estruturação. Neste ensaio, essa concepção permite considerar que a ação dos estrategistas de uma organização é influenciada e influencia o campo organizacional, e também que a adoção de práticas estratégicas pelos estrategistas de uma organização é orientada por regras e recursos existentes no campo organizacional.

Os conceitos abordados são representados mediante uma adaptação do modelo conceitual de integração entre práxis, prática e praticantes - conceitos advindos da estratégia como prática - desenvolvido por Whittington (2006). Ao modificar e complementar esse modelo, apresenta-se, neste ensaio teórico, o modelo conceitual utilizado em uma pesquisa ainda em curso. A esse respeito, apesar de o modelo de Whittington (2006) ter sido amplamente citado, não se encontraram estudos que buscassem complementá-lo ou adaptá-lo.

Este ensaio compõe-se de mais cinco seções, além desta primeira. Na segunda, destaca-se o modelo de Whittington (2006) de integração entre práxis, prática e praticantes. A terceira é destinada à discussão da relação entre ambiente institucional e a adoção de práticas estratégicas pelos estrategistas de uma organização. Na quarta, apresentam-se as contribuições da teoria da estruturação para a proposta neste ensaio, ressaltando os conceitos de recursividade entre agência e estrutura e propriedades estruturais. A quinta é destinada à discussão sobre a integração das abordagens teóricas e apresentação do modelo conceitual proposto. Na sexta, apresentam-se as considerações finais.

\section{Integração entre práxis, prática e praticantes: modelo conceitual de Whittington}

O modelo conceitual proposto neste ensaio teórico foi construído com base no modelo desenvolvido por Whittington (2006) sobre a adoção de práticas estratégicas pelos estrategistas de uma organização: integração entre práxis, prática e praticantes. Apesar de recente, essa publicação é uma das mais citadas em estudos de estratégia como prática (WALTER e AUGUSTO, 2009a).

Por meio desse modelo, Whittington (2006) propõe integrar os níveis intraorganizacional e extraorganizacional baseando-se nos conceitos de práxis de estratégia, de práticas estratégicas e de praticantes em estratégia. A concepção de prática recorre a rotinas compartilhadas de comportamento, incluindo tradições, normas, maneiras de pensar e atitudes, em um sentido mais amplo. As práticas estratégicas são multiníveis. Em nível organizacional, incorporam rotinas, procedimentos operacionais e cultura, formando modos locais de strategizing. Também podem ser oriundas de campos ou sistemas sociais mais amplos nos quais uma organização particular está inserida. Em um nível ainda mais amplo, existem práticas estratégicas de sociedades inteiras.

Praticantes são os atores da estratégia, os estrategistas que executam as atividades de prática estratégica e que fazem a práxis estratégica, ou seja, que realizam atividades envolvidas com a formação, adaptação e execução da estratégia. Atuam como condutores das práticas estratégicas tanto como executivos seniores, quanto como gerentes medianos ou outros atores que se ocupam do trabalho de estratégia. Há, ainda, os conselheiros de estratégia externos à organização, como consultores, banqueiros de investimentos, advogados e gurus acadêmicos (WHITTINGTON, 2006).

A práxis é o que os praticantes realizam de fato. Esse conceito relaciona-se a todas as atividades que os atores executam para formulação e implementação de estratégia. Assim, consiste no trabalho 
intraorganizacional exigido para fazer e executar a estratégia. Esse trabalho é difuso, mas possível de ser observado por meio de episódios ou sucessões de episódios, como reuniões, intervenções de consultorias, instruções para a equipe, apresentações, projetos e conversas. Em síntese, as práticas estratégicas são utilizadas pelos praticantes em sua práxis (WHITTINGTON, 2006).

Na Figura 1, apresenta-se o modelo desenvolvido por Whittington (2006).

\section{Figura 1}

\section{Integração entre práxis, prática e praticantes}

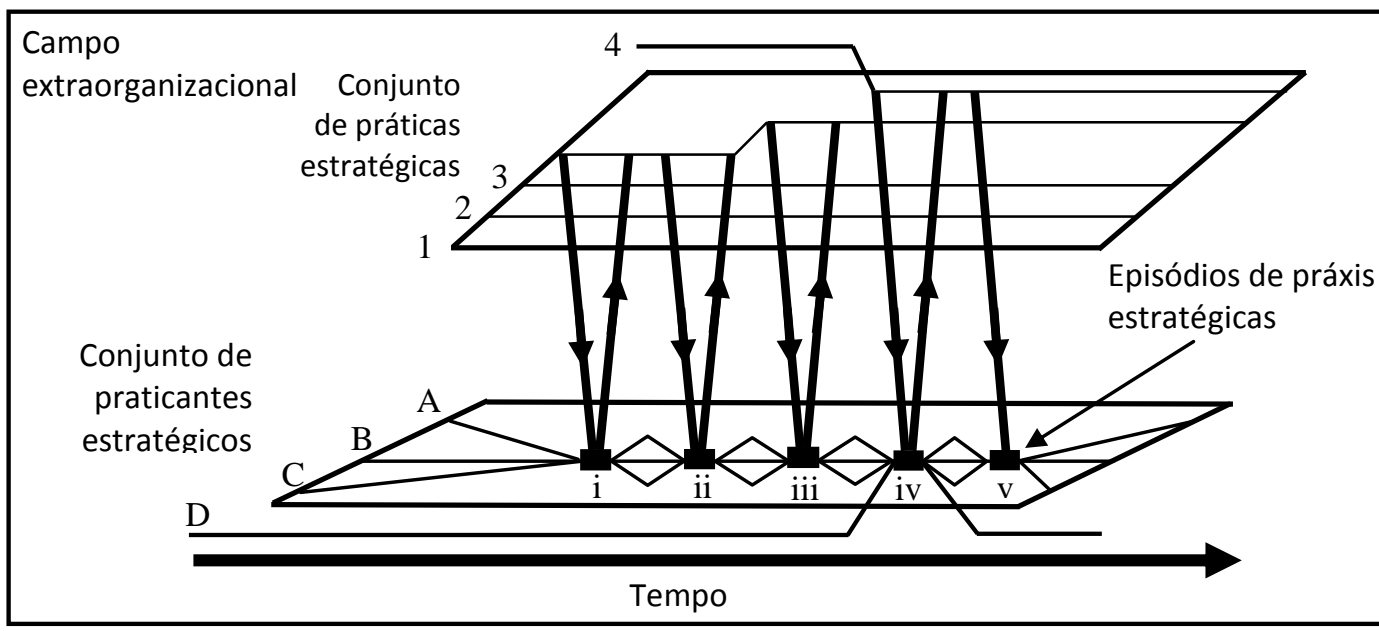

Fonte: Whittington (2006).

No paralelogramo inferior do modelo de Whittington (2006), exposto na Figura 1, os praticantes são representados pelas letras $\mathrm{A}, \mathrm{B}, \mathrm{C}$ e $\mathrm{D}$; os três primeiros são da mesma organização; D, do campo extraorganizacional. Há cinco pontos de convergência em episódios de práxis de estratégia intraorganizacional: de "i" a "v". Esses episódios podem ser formais, como reuniões da diretoria, ou informais, como conversas.

Os praticantes escolhem suas práticas (de 1 a 4) entre as disponíveis no contexto organizacional e extraorganizacional. As práticas legitimadas na organização integram o paralelogramo superior. Conforme pode ser observado, os praticantes A, B e C compartilham as práticas 1,2 e 3 ; no entanto, em algum momento, eles podem alterar uma prática, como ocorre no episódio de práxis ii com a prática 3, representada pela dobra. Como Whittington (2006) destaca, a confiança dos praticantes nas práticas não é passiva: eles podem adaptar práticas existentes e sintetizar práticas novas. Os praticantes podem, também, incorporar uma prática nova - como no episódio iv da prática 4 -, que é trazida para a organização por um praticante extraorganizacional. Assim, a prática 4 representa as práticas que estão fora daquelas aceitas pela organização, mas que integram o seu campo extraorganizacional.

Segundo Whittington (2006), seu modelo tem quatro implicações para estudos de estratégia como prática: uso da prática estratégica; criação de práticas de estratégia; praticantes como portadores de práticas; e preparação de praticantes para a práxis. No tocante à primeira implicação, as setas descendentes sinalizam o peso de práticas em práxis, indicando tanto um conservadorismo quanto a possibilidade de mudança gerada, principalmente, por práticas extraorganizacionais (prática 4). Contudo, no modelo proposto não se sugere que os praticantes sejam submissos às práticas. Ao contrário, elas são adaptáveis na práxis, como representa 
a dobra no episódio ii. Isso levanta o debate sobre como as práticas são usadas pelos estrategistas em sua práxis.

No que se refere à segunda implicação, Whittington (2006) frisa que as setas ascendentes representam que as práticas estratégicas normalmente emergem da práxis, o que também indica conservadorismo. Todavia, algumas práticas têm poder de se difundir para além da organização, o que indica um assunto importante de pesquisa: como tais práticas tornam-se tão influentes? Ressalta-se que, apesar de o autor considerar que as práticas estratégicas possam se difundir para o campo extraorganizacional, esse aspecto não é abrangido por seu modelo. Outra possibilidade de pesquisa destacada pelo autor no tocante a essa implicação é: como surgem práticas novas? A esse respeito, Whittington (2006) defende que os praticantes externos são os produtores mais efetivos de novas práticas.

A respeito da terceira implicação, de acordo com Whittington (2006), o praticante D indica que os estrategistas são centrais na transferência e na inovação de práticas estratégicas. Isso aponta um assunto relevante para pesquisa: a influência dos praticantes na estratégia das organizações.

Por fim, no que tange à quarta implicação, os praticantes são mediadores cruciais entre práticas e práxis. Dessa forma, se esses indivíduos não estiverem preparados e não possuírem conhecimento para atuar na práxis, poderão comprometer profundamente a estratégia da organização. Assim, uma pergunta de pesquisa importante é: como os praticantes são preparados para atuar em episódios de práxis?

Considera-se que a principal contribuição do modelo de Whittington (2006) está em explicar a origem das práticas, isto é, que as práticas de $\mathrm{A}, \mathrm{B}$ e $\mathrm{C}$ são oriundas de um conjunto de práticas que a organização proporciona a seus praticantes. Em contraposição, o praticante D é extraorganizacional e introduz novas práticas na organização, ou seja, práticas ainda não legítimas entre seus praticantes internos.

Após publicação, o estudo de Whittington (2006) foi empregado em algumas pesquisas baseadas na perspectiva da estratégia como prática, contudo de forma fragmentada, com foco em alguns aspectos do modelo. Klag (2010), por exemplo, empregou os conceitos de práxis, práticas e praticantes do modelo de Whittington (2006) para analisar três casos de fracasso no desenvolvimento de estratégias organizacionais. O autor identificou os seguintes elementos que contribuíram para as falhas nas estratégias: falta de boa vontade e receptividade para dedicar-se a práticas estratégicas baseadas em práticas institucionalizadas que não se ajustavam a tais iniciativas; estrategistas incapazes de desenvolver a estratégia ou não comprometidos com o strategizing; e práxis ineficaz.

Vásquez (2010), por sua vez, propõe complementar o modelo de Whittington (2006) e inserir mais um elemento essencial da prática estratégia: o texto estratégico. Para o autor, a produção e o consumo de textos estratégicos são elementos fundamentais da estratégia, pois articulam atividades locais e práticas institucionalizadas.

Em alguns estudos também se enfocou o papel de estrategistas externos à organização com base no modelo de Whittington (2006). Neste sentido, Walter e Augusto (2009b) verificaram o papel desempenhado por consultores no strategizing de uma organização bancária. Os resultados obtidos permitiram inferir cinco proposições teóricas, sendo três relacionadas ao processo de atuação das consultorias: variabilidade no grau de atuação e responsabilidade; promoção de aprendizado; e customização em diferentes níveis. As outras duas referem-se ao papel dos consultores no strategizing: legitimador e isomórfico.

Pascucci e Augusto (2010) empregaram o modelo conceitual de Whittington (2006) no tocante aos estrategistas externos para investigar o papel de consultores empresariais na formação, na adoção e na legitimação de ferramentas e de práticas de estratégia. Os autores observaram que os consultores 
têm uma influência significante na adoção de práticas estratégicas nas organizações, desempenhando papéis de articulação, integração e execução.

Assim, nota-se que o estudo de Whittington (2006) e os estudos posteriores baseados em seu modelo exploram, no tocante ao ambiente extraorganizacional, apenas como as práticas extraorganizacionais são inseridas nas organizações por meio de estrategistas externos, desconsiderando que os estrategistas internos também adotam práticas estratégicas oriundas do campo organizacional por meio de outros mecanismos alheios à atuação de atores externos. Neste ensaio, considera-se que os estrategistas internos adotam práticas estratégicas do campo organizacional por meio de diferentes mecanismos isomórficos, como é discutido na próxima seção.

\section{Ambiente institucional e adoção de práticas estratégicas}

Conforme se destacou, o conceito de isomorfismo, neste ensaio, contribui para a compreensão da relação existente entre o ambiente institucional, que pode ser delimitado como um campo organizacional, e a adoção de práticas estratégicas pelos estrategistas de uma organização. Isso é possível porque, como se discute nesta seção, os mecanismos isomórficos institucionais podem influenciar o processo de adoção de práticas estratégicas pelos estrategistas.

O processo de isomorfismo, em consonância com Hawley (1968 apud DIMAGGIO e POWELL, 1983), consiste em as unidades de uma população serem levadas a se assemelharem a outras unidades que estão sob o mesmo conjunto de condições ambientais. Nesse sentido, DiMaggio e Powell (1991) destacam a relação entre estabilidade e legitimidade, como também o poder de padrões comuns dificilmente articulados de forma explícita, mas que levam à tendência de tornarem as organizações homogêneas.

DiMaggio e Powell (1983), baseando-se na noção de estruturação de Giddens (2003), fazem as seguintes afirmações: essa forma de homogeneização advém da estruturação de campos organizacionais; quando os campos organizacionais surgem, caracterizam-se pela diversidade de formas e abordagens; à medida que o campo se estabelece, há uma tendência à homogeneização. Esse processo de homogeneização da população de um campo organizacional consiste na alteração das características organizacionais de maneira a se assemelharem, de forma crescente, com o ambiente.

De acordo com Meyer e Rowan (1977), existem duas explicações para o isomorfismo relacionadas ao ambiente (técnico ou institucional): organizações formais dependem de outras do mesmo ambiente para realização de trocas ou por refletirem a realidade socialmente construída. Com base nisso, sob a ótica de Meyer (1979), Fennell (1980) e DiMaggio e Powell (1983), há dois tipos de isomorfismo: competitivo e institucional.

Como exemplo de autores que abordam o isomorfismo competitivo, DiMaggio e Powell (1983, p. 77) apontam Hannan e Freeman (1977), que supõem uma racionalidade sistêmica e enfatizam "a competição no mercado, a mudança de nichos e medidas de adequação". DiMaggio e Powell (1983) frisam que essa perspectiva de isomorfismo é compatível com campos organizacionais em que a competição é livre e aberta, além de explicar o processo de burocratização observado por Weber e ser aplicável à adoção antecipada de inovações.

Em contraposição, o isomorfismo institucional considera que as organizações não competem somente por recursos e clientes, mas por legitimação, poder político, adequação social e econômica. Assim, essa perspectiva constitui uma base útil para a compreensão da política e do cerimonial que permeiam parte considerável da vida organizacional moderna (DIMAGGIO e POWELL, 1983). 
DiMaggio e Powell (1983) apresentam três mecanismos que fomentam isomorfismo institucional: coercitivo, derivado de influências políticas e legais; mimético, oriundo da imitação organizacional diante da incerteza ambiental; e normativo, derivado, principalmente, de aspectos da profissionalização, como normas, regulamentos e métodos de trabalho.

$\mathrm{O}$ isomorfismo coercitivo resulta de pressões formais e informais exercidas por organizações sobre organizações que delas dependem. Essas "pressões podem ser sentidas como coerção, como persuasão, ou como um convite para se unirem em conluio" (DIMAGGIO e POWELL, 1983, p. 77).

As organizações têm por opção, ainda, tomar outra organização como modelo na formulação de suas práticas, o que consiste no processo de isomorfismo mimético. Ou imitar práticas bem-sucedidas no campo para ampliar sua legitimidade. Esse processo também pode ocorrer de forma involuntária, por meio da transferência de funcionários ou da contratação de consultorias (DIMAGGIO e POWELL, 1983).

O isomorfismo normativo ocorre, principalmente, por meio da atuação das profissões, porque, como assinalam DiMaggio e Powell (1983), organizações, ainda que diferentes umas das outras, possuem um quadro de profissões similar. Nesse sentido, as profissões atuam como agentes isomórficos em decorrência de formação em comum, da atuação em entidades de classe e em outras instituições, bem como da simples leitura de revistas especializadas.

Segundo DiMaggio e Powell (1983), essa distinção entre os três tipos de isomorfismo é analítica, visto que esses três mecanismos não são empiricamente distintos e ocorrem concomitantemente. Slack e Hinings (1994) - em um estudo sobre a adesão de organizações esportivas canadenses a um programa governamental que conduzia à especialização, à profissionalização e à burocratização - verificaram que esses três mecanismos isomórficos se reforçaram mutuamente, aumentando a pressão à adesão.

Além disso, DiMaggio e Powell (1983) também argumentam que, enquanto se misturam no cenário empírico, os três tipos de isomorfismo tendem a derivar de condições diferentes e conduzir a resultados distintos. Esses autores citam o seguinte exemplo: atores externos podem induzir uma organização a se conformar a seus semelhantes, exigindo que esta execute uma tarefa particular e especificando a profissão responsável pelo seu desempenho. Com base nos autores, acredita-se que a diferenciação entre os três mecanismos possa existir no tocante à forma como ocorre o isomorfismo, e não aos aspectos difundidos. Portanto, argumenta-se que o fundamental, ao analisar a ocorrência desses mecanismos, é verificar de que condições o isomorfismo deriva, ou seja, de que forma a homogeneização ou difusão ocorre, e não em qual dimensão ocorre.

Diante do apresentado sobre o conceito de isomorfismo, neste ensaio se compreende o isomorfismo institucional como a adoção, pela organização, de práticas estratégicas oriundas de outros atores do campo organizacional por meio de mecanismos isomórficos: o mimético, o coercitivo e o normativo.

Também é importante destacar concepções adotadas neste ensaio no tocante ao isomorfismo institucional para fundamentar a construção do modelo proposto. A primeira refere-se à ideia de que a incorporação das práticas estratégicas pela organização não ocorre de forma determinista. Conforme Oliver (1991), as organizações possuem capacidade de responder às pressões para mudanças oriundas do campo organizacional. Assim, defende-se que a organização possa apresentar diferentes respostas às pressões isomórficas exercidas pelo campo no que tange à adoção de práticas estratégicas.

Tem-se, ainda, a ideia de adaptação, pela organização, das práticas adotadas do campo, que consiste na segunda concepção que se adotou neste ensaio quanto ao conceito de isomorfismo. Como destacado por Wooten e Hoffman (2008), integrantes do campo organizacional podem ajustar ou manipular práticas de 
acordo com suas necessidades ou contextos específicos. Essas práticas são traduzidas do nível institucional para o nível organizacional. Nesse sentido, concebe-se que a organização pode se valer de práticas estratégicas existentes no campo - tais práticas normalmente sofrem alguma alteração no sentido de uma adaptação às características e ao contexto da organização. Essa adaptação também pode ser resultante do processo de interpretação realizado pelos estrategistas a respeito da prática estratégica ou, como indicam Czarniawska e Joerges (1996) e Zilber (2006), de tradução do nível institucional para o nível organizacional. Isso ocorre porque, antes de adotar uma prática oriunda do campo organizacional, os estrategistas necessitam interpretá-la, processo que não ocorre de forma homogênea e pode ocasionar alterações na prática original. Assim, as organizações não adotam as práticas estratégicas da forma exata em que ela pode ser encontrada no campo, mas a ajustam aos seus interesses, ao seu contexto e às suas características ou, ainda, as alteram no decorrer da sua interpretação. Essa ideia corrobora a concepção de Whittington (2006) de que as práticas estratégicas podem ser adaptadas pelos estrategistas da organização por meio de sua práxis.

A terceira concepção adotada é a de recursividade entre agência e estrutura, oriunda da teoria da estruturação, apresentada na próxima seção.

\section{Contribuições da teoria da estruturação}

Destacam-se, na sequência, os conceitos advindos da teoria da estruturação que contribuíram para o desenvolvimento do modelo conceitual proposto neste ensaio: recursividade entre agência e estrutura e propriedades estruturais do campo organizacional.

De acordo com Giddens (2003, p. 20), a estrutura, no seu significado mais elementar, refere-se a regras e recursos de transformação que governam a "matriz de transformações admissíveis dentro de um conjunto". Assim, refere-se "às propriedades de estruturação que permitem a 'delimitação' de tempo-espaço em sistemas sociais, às propriedades que possibilitam a existência de práticas sociais discernivelmente semelhantes por dimensões variáveis de tempo e de espaço".

Tratar a estrutura como uma ordem virtual significa que ela ocorre em exemplificações nas práticas, como presença no espaço e no tempo. Além disso, existe enquanto traços mnêmicos que orientam a conduta de agentes dotados de capacidade cognoscitiva. Nota-se que a estrutura não consiste em algo concreto. Por isso, sistemas sociais, como práticas sociais reproduzidas, não possuem estruturas, mas propriedades estruturais. 'Princípios estruturais' é o termo que Giddens (2003) utiliza para se referir às propriedades estruturais mais profundamente embutidas que implicam a reprodução de totalidades sociais e expressam formas de dominação e poder. Como instituições, podem ser consideradas as práticas que possuem maior extensão espaço-temporal.

Giddens (2003, p. 22) desfaz "o caráter fixo ou mecânico" costumeiramente atribuído ao termo 'estrutura'. Para o autor, as regras e os recursos empregados na produção e na reprodução da ação social são, concomitantemente, os meios de reprodução do sistema, o que está relacionado ao conceito de dualidade de estrutura, destacado a seguir. Assim, tanto a estrutura auxilia a formulação de uma ação isolada, quanto tal ação, constrói a estrutura. No âmbito da estrutura, as regras devem ser consideradas conjuntamente com os recursos. Esses se referem aos modos pelos quais as relações transformadoras são incorporadas à produção e à reprodução de práticas sociais (GIDDENS, 2003). As regras atuam não apenas na constituição de significado mas também no sancionamento de maneiras de conduta social.

Muitas vezes, as regras são equiparadas a hábitos ou rotinas. Giddens (2003), porém, destaca, em sua definição, que as regras recaem sobre diversos aspectos da prática rotineira, mas que esta não pode ser considerada uma regra. As regras também podem ser consideradas quanto a dois outros aspectos: sua 
influência na construção de significado e sua relação com sanções. Contudo, as regras são procedimentos de ação, ou seja, aspectos da práxis. Essa relação entre regras e práxis é importante para os teóricos de estratégia como prática. Por fim, Giddens (2003) compara seu conceito de regras ao de fórmulas: as regras da vida social são como procedimentos ou técnicas - que podem ser generalizados - aplicados no desempenho e na reprodução de práticas sociais.

Para explicar a relação entre fórmulas e práticas sociais, Giddens (2003) aponta que a consciência de regras sociais - expressa, principalmente, na consciência prática - é o âmago da "cognoscitividade" que caracteriza os agentes humanos. Ademais, para resolver situações da vida social no decorrer de suas atividades diárias, os atores empregam, de forma rotineira, esquemas simbolizados ou fórmulas (SCHUTZ s.d. apud GIDDENS, 2003).

O autor realiza uma distinção entre regras intensivas e superficiais. As primeiras são tácitas, informais e fracamente sancionadas, consistindo em fórmulas empregadas constantemente no decorrer das atividades cotidianas, como as regras da linguagem. Já as regras superficiais possuem um escopo mais amplo, são discursivas, formalizadas e fortemente sancionadas, não obstante tenham "um impacto apenas superficial sobre boa parte da textura da vida social" (GIDDENS, 2003, p. 26).

A maior parte das regras envolvidas com práticas sociais é, para Giddens (2003), apreendida tacitamente pelos atores, ou seja, eles sabem como "prosseguir". A formulação das regras, de forma discursiva, consiste em uma interpretação sobre elas, podendo alterar sua aplicação.

As leis, segundo Giddens (2003), são exemplos de regras sociais discursivamente formuladas e formalmente sancionadas e estão entre as mais fortemente sancionadas. No entanto, também não se pode "subestimar a força de sanções informalmente aplicadas" (GIDDENS, 2003, p. 27). As regras mais importantes são as práticas institucionalizadas, ou seja, as mais profundamente sedimentadas no tempo-espaço.

Diante do que foi apresentado, pode-se inferir que os estrategistas das organizações interpretam e adotam práticas estratégicas orientados pelas regras existentes na estrutura do campo organizacional com a intenção de obter recursos por meio dele. Igualmente se acredita que a interpretação e a adoção dessas práticas estratégicas também possam ocasionar transformações na estrutura do campo, como será discutido a seguir, com a apresentação do conceito de recursividade entre agência e estrutura.

Giddens (2003, p. 30), ao formular a teoria da estruturação, apresenta a ideia de dualidade da estrutura, segundo a qual "as propriedades estruturais de sistemas sociais são [...] meio e fim das práticas que elas recursivamente organizam". O mecanismo ou o processo por meio do qual a dualidade da estrutura opera é o de recursividade entre agência e estrutura. Assim, a estrutura tanto restringe quanto fornece as condições que possibilitam a ação. Isso ocorre porque, sem as regras e sem os recursos fornecidos pela estrutura, a ação do indivíduo é impossibilitada e se restringe na medida em que a transgressão das regras pode ocasionar sanções. Percebe-se que essa concepção foi adotada pela teoria institucional para explicar a relação entre a agência e o ambiente institucional. Neste ensaio teórico, essa ideia é empregada para discutir a influência mútua existente entre a atuação dos estrategistas das organizações e o campo organizacional.

De acordo com Giddens (2003), não se pode afirmar que as propriedades estruturais de sistemas sociais sejam produtos sociais, porque isso poderia indicar que os atores se reúnem para criá-las. Apesar disso, a estrutura não existe sem o conhecimento dos agentes, no nível da consciência discursiva, a respeito do que fazem em sua atividade cotidiana.

Ainda segundo a teoria da estruturação, a realização da ação acarreta a "reprodução nos contextos do desempenho cotidiano da vida social", e a interação dentro do contexto é inerente à reprodução social (GIDDENS, 2003, p. 31). Dessa forma, a ação proporciona a sobrevivência da estrutura por meio da sua reprodução no tempo e no espaço, reproduzindo as condições que permitem a ação. Por esse motivo, a 
dualidade da estrutura pressupõe a monitoração reflexiva dos agentes na atividade social cotidiana. Giddens (2003) acrescenta que as práticas rotinizadas são fundamentais para a continuidade da vida social.

Para Giddens (2003), as ações humanas frequentemente geram consequências não intencionais. Nesse sentido, podem ser feitas as seguintes observações: a ação possui consequências, e parte destas não é premeditada por causa da complexidade da sociedade; as relações sociais são tão complexas que não se pode estabelecer uma relação de causa e efeito linear; a ação, em virtude de sua imersão social, provoca consequências que nunca foram previstas.

Transportando esse conceito para a relação existente entre atuação dos estrategistas da organização e campo organizacional, tem-se a compreensão de que os estrategistas realizam e interpretam ações de modo que acabam por interferir no campo e, ao mesmo tempo, são afetados por ele.

Em síntese, discutiu-se, até o momento, que o modelo de Whittington (2006) procura explicar o processo de adoção de práticas estratégicas pelos estrategistas das organizações, mas não considera que os estrategistas internos possam adotar práticas estratégicas oriundas do campo organizacional. Dessa forma, apresentaramse os mecanismos isomórficos institucionais como possível fenômeno por meio do qual a adoção de práticas estratégicas do campo organizacional é feita pelos estrategistas da organização. Também se destacou que esse processo de adoção e de adaptação de práticas estratégicas é influenciado e influencia o campo organizacional. Por fim, ressaltou-se que as regras e os recursos que compõem as propriedades estruturais do campo organizacional podem atuar como orientadores do processo de adoção de práticas estratégicas pelos estrategistas de uma organização. A seguir, realiza-se a interconexão entre todos esses aspectos.

\section{Integração das abordagens teóricas e o modelo proposto}

Expõem-se, agora, como as abordagens institucionais e da estratégia como prática podem ser integradas, empregando-se elementos mediadores da teoria da estruturação. Explica-se, também, o modelo conceitual proposto para relacionar os âmbitos micro e macro da estratégia.

$\mathrm{Na}$ abordagem institucional tende-se a compreender as organizações como fenômenos sociais sujeitos a questões de estabilidade e de mudança. Na estratégia, esse olhar sociológico consolida-se na perspectiva da estratégia como prática social. Assim, uma possibilidade de colocar as duas perspectivas em conversação é empregar uma base sociológica, fundamentando-se na perspectiva de prática em estratégia.

Acredita-se que relacionar a perspectiva da estratégia como prática e a abordagem institucional seja um meio consistente e aprofundado de integrar os níveis de análise micro e macro. Nesse sentido, a abordagem institucional pauta-se no entendimento de que a realidade é socialmente construída e que o acesso a essa realidade se dá por meio do conhecimento da dimensão intersubjetiva. De acordo com Berger e Luckmann (1967), reconhece-se a existência de uma realidade socialmente construída, uma vez que são as próprias pessoas, por meio de suas interações e ações, que legitimam essa realidade como objetiva e subjetivamente a internalizam ao longo de inúmeros processos de socialização.

As pesquisas relacionadas a essa perspectiva concentram-se em níveis de análise que possam revelar a dimensão intersubjetiva de significados compartilhados e que dotam a vida social de sentido, ou seja, tendem a focar mais o âmbito macro. No entanto, atualmente, emerge um debate, no que tange à perspectiva institucional, sobre a dimensão micro de análise organizacional. Apesar disso, como destacam Palmer, 
Biggart e Dick (2008), uma compreensão teórica do nível micro tem sido fracamente desenvolvida pelo institucionalismo.

Em contraposição, a abordagem de estratégia como prática - embora busque relacionar os níveis da estratégia - ao focar o âmbito micro das organizações, arrisca-se a se limitar muito a esse aspecto (WHITTINGTON, 2006). Dessa formaas perspectivas institucionais e da estratégia como prática podem se complementar de forma que a conversação entre elas possibilite estabelecer uma relação entre o âmbito micro e o macro de análise da estratégia.

No tocante à integração das abordagens teóricas para estudo do isomorfismo, destaca-se que Giddens (2003) considera a prática como algo social e independente do indivíduo, e que, segundo Whittington (2006), a perspectiva de estratégia como prática evidencia que as práticas estratégicas de uma organização podem advir tanto do contexto organizacional quanto do extraorganizacional ou institucional. Isso significa que as práticas estratégicas podem ser oriundas do campo organizacional e empregadas pelas organizações, possivelmente, por meio de um processo de isomorfismo. Além disso, a contribuição da teoria da estruturação para o estudo do isomorfismo de um campo já foi destacada por DiMaggio e Powell (1983), para os quais esse processo de homogeneização surge da estruturação de campos organizacionais, em que, quanto mais estabelecido o campo, maior a homogeneidade.

Diante desse contexto, percebe-se a possibilidade de interligar as abordagens de estratégia como prática e institucional para verificar a influência dos mecanismos isomórficos na adoção de práticas estratégicas pelas organizações. Para representar essa integração entre as perspectivas teóricas empregadas neste ensaio, optouse por modificar e ampliar o modelo de Whittington (2006), já destacado anteriormente.

No tocante ao modelo apresentado por Whittington (2006), destaca-se que ele explora apenas como as práticas extraorganizacionais são inseridas nas organizações por meio de estrategistas externos, desconsiderando que os estrategistas internos também adotam práticas estratégicas oriundas do campo organizacional por meio de outros mecanismos alheios à atuação de atores externos. Além disso, apesar de o autor indicar a existência de um nível que extrapola o organizacional, ele não o explora detalhadamente.

Realizou-se, então, uma adaptação do modelo de Whittington (2006) para incluir o campo organizacional e para a inserção, na organização, de práticas estratégicas oriundas desse campo por meio dos estrategistas internos e externos. Objetiva-se, com essa adaptação do modelo, abarcar os três níveis da estratégia, bem como a influência dos mecanismos isomórficos institucionais sobre a adoção de práticas estratégicas pelos estrategistas da organização. O modelo conceitual proposto é apresentado na Figura 2. 
Figura 2

Adoção de práticas estratégicas por estrategistas da organização

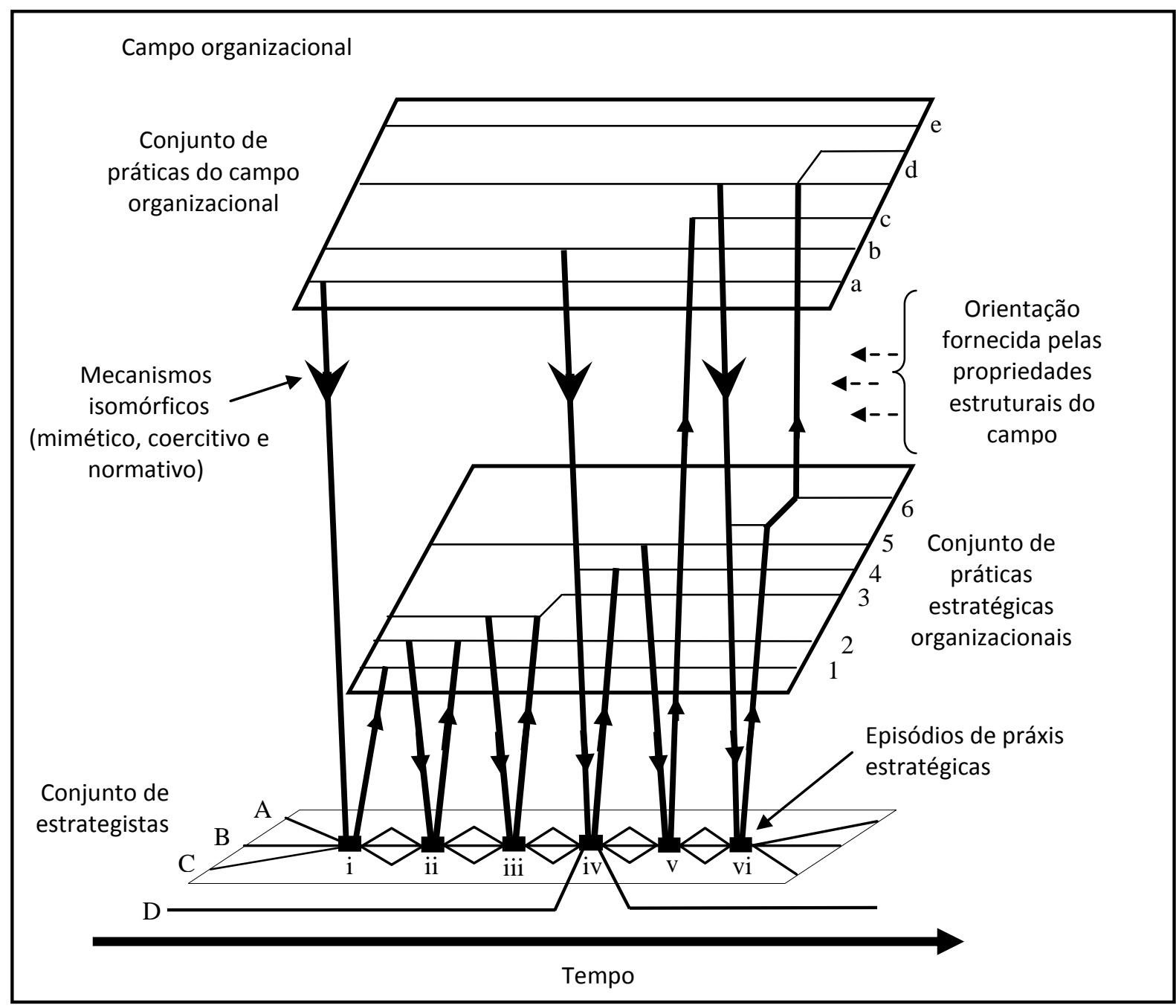

Fonte: Adaptado de Whittington (2006).

Conforme se pode notar na Figura 2, em comparação com o modelo original de Whittington (2006), optou-se pela denominação de campo organizacional para representar o que o autor denominava de campo extraorganizacional. Essa opção visa adequar esse modelo aos propósitos neste ensaio, visto que se emprega o conceito de campo organizacional como recorte de um âmbito mais amplo, ou seja, do ambiente institucional. Nesse sentido, o campo organizacional é empregado para delimitar as fronteiras dos fenômenos citados no modelo, visto que todos os que foram apresentados no modelo estão inseridos em um mesmo campo organizacional.

Assim como no modelo de Whittington (2006), os níveis da estratégia são representados pelos paralelogramos. Entretanto, para complementar o modelo original, realizou-se a inserção de mais um nível da estratégia: o conjunto de práticas do campo organizacional, representadas pelas letras minúsculas (de "a" até "e"). Logo, o conjunto de práticas do campo organizacional (de "a" até "e") representa o nível institucional; o conjunto de práticas estratégicas organizacionais (de 1 a 6), o nível organizacional; e o 
conjunto de praticantes estratégicos (ou estrategistas) (de A a D) realizando seus episódios de práxis estratégicas (de "i" a "vi”), o nível da práxis estratégica (micro).

Outra alteração realizada foi a diferenciação dos pontos de partida e de chegada das setas nas práticas estratégicas da organização. No modelo original (vide Figura 1), as setas existentes nas práticas estratégicas (nível organizacional) se originavam e se dirigiam apenas para as práticas 3 e 4 . Buscando aprofundar o entendimento do modelo conceitual, optou-se por posicionar cada conjunto de setas (ascendente e descendente) em uma prática estratégica organizacional. Essa adaptação objetivou facilitar a compreensão no sentido de que podem existir diferentes práticas estratégicas na organização e na visualização das diferentes possibilidades de origem e do caminho percorrido, pelas práticas estratégicas, na busca da relação existente entre o ambiente e a adoção de práticas estratégicas por meio dos mecanismos isomórficos.

O papel das setas também foi expandido em relação ao modelo original: passaram a interligar os três níveis da estratégia - práxis, organizacional e campo organizacional - e, consequentemente, a representar diferentes fenômenos, como o caso do isomorfismo. Além disso, foi expandido o número de episódios de práxis - de $\mathrm{V}$ para VI - e de práticas organizacionais - de 4 para 6 - para abranger essas diferentes possibilidades de interação entre os níveis da estratégia.

As setas ascendentes e descendentes que conectam os episódios de práxis dos estrategistas e o conjunto de práticas organizacional, já existentes no modelo de Whittington (2006), representam a influência mútua entre esses dois níveis. Dessa forma, as práticas estratégicas influenciam a práxis dos estrategistas atuando como um script que guia as ações utilizadas por eles na sua atividade cotidiana (WHITTINGTON, 2006; JARZABKOWSKI; BALOGUN; SEIDL, 2007). Os estrategistas, por sua vez, colocam em uso, em sua práxis cotidiana, as práticas estratégicas da organização, reforçando-as e adaptando-as, de forma a lhes garantir a legitimidade para que estas se tornem um padrão persistente no tempo e no espaço (GIDDENS, 2003). Como representação (já existente no modelo original) dessa adaptação que os estrategistas podem realizar em uma prática estratégica, tem-se o episódio de práxis iii, após o qual a prática organizacional 3 sofre uma alteração como demonstrado pela dobra.

Já as setas que interligam o conjunto de práticas do campo organizacional - representadas pelas letras de "a" até "e" - aos demais níveis não existiam no modelo original. Como pode ser observado na Figura 1, no modelo de Whittington (2006) a única conexão existente com o campo extraorganizacional consiste em uma prática estratégica (prática 4) que é inserida, na organização, por meio de um praticante externo. Assim, de acordo com a proposta neste ensaio e como forma de complementar o modelo original, as setas descendentes do conjunto de práticas do campo organizacional - da letra "a" até a letra "e" - para os demais níveis (destacadas com pontas de setas maiores) são vistas como a influência de mecanismos isomórficos. Dessa forma, considera-se que práticas do campo organizacional possam ser adotadas pelos estrategistas e pela organização por meio da atuação desses mecanismos isomórficos.

Também se considera que esse processo de adoção, pelos estrategistas e pela organização, das práticas oriundas do campo organizacional é orientado pelas propriedades estruturais do campo organizacional. Assim, os estrategistas guiam-se por padrões e procedimentos generalizáveis e normativos do campo organizacional que orientam e que sancionam a adoção de práticas estratégicas, ou seja, guiam-se por regras. Além disso, os estrategistas mobilizam meios, considerados como recursos, para a adoção das práticas estratégicas.

A prática do campo organizacional "a" é adotada pelos estrategistas da organização no episódio de práxis "i" por meio de um processo isomórfico institucional, tornando-se a prática estratégica 1 da organização. Isso pode ocorrer porque os estrategistas podem tomar conhecimento de práticas estratégicas que obtiveram sucesso em outras organizações do campo, uma vez que mantêm contato com indivíduos externos à sua organização, seja por meio de amizades, da participação em entidades, e de visitas a feiras, a exposições e a outras empresas. Nesse caso, pode-se considerar que há uma ocorrência de isomorfismo mimético. Outra 
possibilidade é a ocorrência do mecanismo isomórfico normativo, ou seja, que os estrategistas conheçam a prática estratégica em virtude de sua profissão, por meio do ensino formal (formação técnica ou acadêmica), da atuação em entidades de classe e em outras instituições e da leitura de revistas especializadas. Ressalta-se que a ocorrência de um dos mecanismos isomórficos não descarta os demais, visto que a divisão desses mecanismos é analítica e que estes podem ocorrem em conjunto (DIMAGGIO; POWELL, 1983).

A prática do campo organizacional "b" é inserida na organização por meio do estrategista externo D, incorporada no episódio de práxis "iv" e difundida para os estrategistas internos (de A até C), tornando-se a prática organizacional 3. Esse processo já havia sido explorado no modelo de Whittington (2006). Contudo, acrescenta-se que tal ocorrência também pode ser fruto de um mecanismo isomórfico. Como destacam DiMaggio e Powell (1983), pode ocorrer um processo de isomorfismo mimético involuntário na organização por meio da transferência de funcionários ou da contratação de consultorias. Nesse sentido, um funcionário recém-contratado (que ainda não compactua com as práticas organizacionais como os estrategistas internos), um consultor ou outro agente externo podem atuar como condutores de um mecanismo isomórfico mimético.

A adoção da prática do campo organizacional "d", que depois de adotada pelos estrategistas da organização torna-se a prática estratégica organizacional 6 , pode ser decorrente de qualquer um dos três mecanismos isomórficos ou de qualquer conjunto deles, tanto dos já destacados (mimético e normativo) quanto do coercitivo. Esse último pode ser oriundo de uma pressão exercida por um integrante do campo organizacional do qual a organização depende para obter um recurso fundamental. Esse integrante pode ser um órgão regulador ou um cliente ou um fornecedor insubstituível. O não atendimento a esta pressão pode resultar em sanções, como multas, imagem negativa e perda de legitimidade perante o campo organizacional e/ou perda do fornecedor ou do cliente (DIMAGGIO; POWELL, 1983).

Ainda no tocante à adoção da prática do campo organizacional "d", destaca-se que esta prática consiste em uma representação de que as práticas oriundas do campo organizacional por meio de um mecanismo isomórfico também podem ser adaptadas pelos estrategistas das organizações em um episódio de práxis, ou seja, em nível micro. Assim, essa prática é colocada em uso no episódio de práxis "vi” e sofre uma alteração, como representado pela dobra na prática estratégica organizacional 6. Essa adaptação também pode ser difundida para o campo organizacional, como será destacado a seguir.

As setas ascendentes do nível organizacional para o do campo organizacional, que culminam nas práticas "c" e "d" do campo organizacional, representam a influência das organizações sobre as práticas deste. Nesse sentido, uma prática organizacional pode ser difundida para o campo organizacional e nele se tornar legítima, transformando-se em uma prática do campo organizacional. Assim, a prática organizacional 5 foi criada na organização e difundida para o campo organizacional, tornando-se a prática "c" do campo organizacional, a qual, anteriormente, não existia no campo. Já a prática estratégica 6 - representada, na Figura 2, pela dobra , que era oriunda do campo organizacional, sofreu uma adaptação dentro da organização, que também pode ser difundida para o campo organizacional. Dessa forma, no campo organizacional, poderão ser encontradas a prática em sua forma original e a prática adaptada.

O conjunto das setas descendentes e ascendentes que conectam o nível organizacional e o nível do campo organizacional representa, na teoria da estruturação, a ideia de recursividade entre agência e estrutura.

Ainda no tocante ao conjunto de práticas do campo organizacional, enfatiza-se que nem todas essas práticas são adotadas pela organização. Algumas delas, como, por exemplo, a prática "e", não chegam a ser adotadas pela organização, não obstante permaneçam existindo no campo.

Destacou-se, nesta seção, o modelo conceitual proposto para conexão entre os níveis micro e macro da estratégia, o que permitiu explicar a adoção de práticas estratégicas pelos estrategistas de uma organização. Ressaltou-se que os estrategistas podem adotar uma prática do campo organizacional por meio da ocorrência de mecanismos isomórficos institucionais; que as regras e recursos (propriedades estruturais) podem orientar 
a adoção dessas práticas; e que a atuação dos estrategistas é influenciada e influencia o campo organizacional (recursividade entre agência e estrutura).

\section{Conclusões}

Neste ensaio teórico buscou-se apresentar uma possibilidade de integração entre as perspectivas institucional e da estratégia como prática, com mediação da teoria da estruturação. Como se destacou, a primeira tende mais a focar níveis macros e busca, atualmente, abordar mais âmbitos micros. A estratégia como prática procura relacionar os níveis da estratégia, mas tende a se limitar mais a âmbitos micros, encontrando dificuldade em integrá-los a níveis mais amplos. Isso permite perceber que, nessas duas perspectivas, buscase estender seu enfoque de forma que uma possa auxiliar na complementação da outra.

Nesse contexto, visando contribuir para essas duas áreas do conhecimento e construir uma visão mais abrangente da estratégia em seus diferentes níveis, elaborou-se um modelo conceitual por meio da complementação e adaptação do modelo de Whittington (2006). O modelo que se elaborou, apresentado na Figura 2, integra a adoção de práticas estratégicas por estrategistas de uma organização (estratégia como prática) ao conceito de mecanismos isomórficos institucionais (abordagem institucional). Além disso, o modelo proposto emprega os conceitos de recursividade entre agência e estrutura e de propriedades estruturais do campo organizacional advindos da teoria da estruturação para contribuir no entendimento da relação existente entre os diferentes níveis.

Mediante o apresentado, conclui-se que as abordagens da estratégia como prática e institucional podem ser integradas como forma de ampliar seus enfoques. Isso poderá contribuir para que os estudos realizados sob essas perspectivas não se limitem a um nível de análise, mas busquem relacionar os fenômenos analisados em seus diferentes âmbitos e influências. Assim, essas abordagens poderão alcançar maior grau de conhecimento acumulado e de amadurecimento.

Cabe ressaltar as possibilidades de pesquisa baseadas no modelo teórico proposto. Nesse sentido, o foco nas setas ascendentes entre as práticas organizacionais e a práxis dos estrategistas permite a análise da influência dos estrategistas internos e externos e seus episódios de práxis na estratégia da organização. Como destacado na seção anterior, os estrategistas podem, em conjunto ou individualmente, criar e adaptar práticas estratégicas da organização, além de adotar práticas oriundas do campo organizacional e difundi-las para o restante dos estrategistas. O processo de interação dos estrategistas no strategizing, por exemplo, é uma possibilidade a ser explorada. Também é possível verificar como os estrategistas se articulam internamente para ultrapassar possíveis barreiras da organização a ações desejadas. Dessa forma, considera-se importante analisar o papel desse nível da práxis, lembrando, contudo, de relacioná-lo com o nível organizacional para não se restringir ao nível micro.

Em contraposição, as setas descendentes entre as práticas organizacionais e a práxis dos estrategistas destacam a possibilidade de estudar a influência das práticas estratégicas legitimadas na organização sobre a práxis dos estrategistas. Por estarem inseridos em uma organização dotada de estrutura, cultura, poder e regras, esses aspectos interferem na atuação dos estrategistas, podendo fornecer recursos para a criação, adoção e adaptação de práticas estratégicas em sua práxis, bem como impor regras sobre tais procedimentos.

As setas descendentes oriundas do conjunto de práticas do campo organizacional representam as práticas estratégicas advindas do campo organizacional e adotadas pelos estrategistas da organização por meio da ocorrência de mecanismos isomórficos e sob a orientação das regras e recursos do campo organizacional (propriedades estruturais). 
O processo de adaptação das práticas estratégicas realizado pelos estrategistas, como representado pelas práticas organizacionais 3 e 6 , também merece ser investigado. Pode ser relevante identificar o que influencia a decisão de adaptar ou não uma prática a ser adotada e como esse processo é realizado nas organizações. Os consultores, por exemplo, podem sugerir diversas práticas estratégicas oriundas de outras organizações e o papel deles tem sido pouco explorado em pesquisas na área. Assim, poder-se-ia verificar se essas práticas são adaptadas para a adoção pela organização e, em caso afirmativo, quem são os envolvidos (consultor e/ou organização) e como ocorre o processo de adaptação.

Destaca-se, ainda, como possibilidade de pesquisa, analisar a difusão das práticas estratégicas criadas ou adaptadas pelos estrategistas de uma organização para o campo organizacional. Esse processo foi representado na Figura 2 por meio das setas ascendentes entre as práticas organizacionais e as práticas do campo organizacional. Também nesse caso, o isomorfismo institucional poderia ser empregado como fenômeno para explicar esse processo. Isso porque a difusão de uma prática estratégica de uma organização para o campo organizacional poderia ocorrer por meio da imitação por outras organizações do campo da prática em questão, caracterizando-se a ocorrência de um mecanismo isomórfico mimético. Além desse, os outros mecanismos isomórficos institucionais podem, igualmente, gerar a difusão de uma prática estratégica no campo organizacional, como por meio da atuação em um órgão de classe ou de pressão para que determinado órgão regulador crie uma regra em virtude de tal prática.

\section{Referências}

BERGER, P. L.; LUCKMANN, T. The social construction of reality. New York: Doubleday Anchor, 1967.

CZARNIAWSKA, B.; JOERGES, B. Travels of ideas. In: CZARNIAWSKA, B.; SEVÓN, G. (Eds.). Translating organizational change. Berlin: Walter de Gruyter, 1996. p. 13-47.

DIMAGGIO, P.J. Introduction. In: DIMAGGIO, P. J.; POWELL, W. W. (Eds.). The new institutionalism in organizational analysis. Chicago: University of Chicago, 1991. p. 1-38.

; POWELL, W. W. The iron cage revisited: institutional isomorphism and collective rationality in organizational fields. American Sociological Review, v. 48, p. 147-160, 1983.

FENNELL, M. L. The effects of environmental characteristics on the structure of hospital clusters. Administrative Science Quarterly, v. 25, p. 485-510, 1980.

GIDDENS, A. A constituição da sociedade. São Paulo: Martins Fontes, 2003.

HANNAN, M. T.; FREEMAN, J. The population ecology of organizations. American Journal of Sociology, v. 82, n. 5, p. 929-964, 1977.

JARZABKOWSKI, P.; BALOGUN, J.; SEIDL, D. Strategizing: the challenges of a practice perspective. Human Relations, v. 60, n. 5, 2007.

JARZABKOWSKI, P.; SPEE, A. P. Strategy-as-practice: a review and future directions for the field. International Journal of Management Reviews, v. 11, p. 69-95, 2009.

KLAG, M. How formal strategic planning becomes a misguided tool to enable action: the case of a private school system. In: INTERNATIONAL STRATEGY AS PRACTICE WORKSHOP IN NORTH AMERICA, 1, 2010, Montreal. Proceedings... Montreal: HEC, 2010.

MEYER, J. W. The impact of the centralization of educational funding and control on State and local organizational governance. Institute for Research on Educational Finance and Governance, Stanford University, Program Report, 1979. 
MEYER, J. W.; ROWAN, B. Institutionalized organizations: formal structure as myth and ceremony. American Journal of Sociology, v. 83, n. 2, p. 340-363, 1977.

OLIVER, C. Strategic responses to institutional processes. Academy of Management Review, v. 16, n. 1, p. 145-179, 1991.

PALMER, D.; BIGGART, N.; DICK, B. Is the new institutionalism a theory? In: GREENWOOD, R. et al. (Eds.). The Sage handbook of organizational institutionalism. London: Sage Publications, 2008.

PASCUCCI, L.; AUGUSTO, P. O. M. Micro activities and institutionalized practices: the role of business consultants in strategizing. In: INTERNATIONAL STRATEGY AS PRACTICE WORKSHOP IN NORTH AMERICA, 1, 2010, Montreal. Proceedings... Montreal: HEC, 2010.

RECKWITZ, A. Toward a theory of social practices: a development in cultural theorizing. European Journal of Social Theory, v. 5, n. 2, p. 243-263, 2002.

SCHATZKI, T. R.; CETINA, K. K; SAVIGNY, E. V. The practice turn in contemporary theory. London: Routledge, 2001.

SLACK, T.; HININGS, B. Institutional pressures and isomorphic change: an empirical test. Organization Studies, v. 15, n. 6, p. 803-827, 1994.

VÁSQUEZ, C. Discursive displacement: what strategy texts can (and cannot) do. In: INTERNATIONAL STRATEGY AS PRACTICE WORKSHOP IN NORTH AMERICA, 1, 2010, Montreal. Proceedings... Montreal: HEC, 2010.

WALTER, S. A.; AUGUSTO, P. O. M. A institucionalização da estratégia como prática nos estudos organizacionais. In: ENCONTRO DA ASSOCIAÇÃO NACIONAL DE PÓS-GRADUAÇÃO E PESQUISA EM ADMINISTRAÇÃO, 33, 2009, São Paulo. Anais... Rio de Janeiro: ANPAD, 2009a.

O caleidoscópio da estratégia: o papel das consultorias externas no strategizing de uma organização. In: ENCONTRO DE ESTUDOS EM ESTRATÉGIA, 4, 2009, Recife. Anais... Rio de Janeiro: ANPAD, 2009 b.

WHITTINGTON, R. Strategy as practice. Long Range Planning, v. 29, n. 5, p. 731-735, 1996.

Completing the practice turn in strategy research. Organization Studies, v. 27, n. 5, p. 613-634, 2006.

WOOTEN, M.; HOFFMAN, A. J. Organizational fields: past, present and future. In: GREENWOOD, R. et al. (Eds.). The Sage handbook of organizational institutionalism. London: Sage Publications, 2008. p. 130 -147.

ZILBER, T. The work of the symbolic in institutional processes: translation of rational myths in Israeli high tech. Academy of Management Journal, v. 49, p. 281-303, 2006. 